\title{
ADULT RENAL MYOEPITHELIAL HAMARTOMA
}

\author{
C. PETER FISCHER, M.D.
}

KARL R. HERWIG, M.D.

PAUL W. GIKAS, M.D.

From the Departments of Surgery (Section of Urology) and

Pathology, University of Michigan Medical Center,

Ann Arbor, Michigan

\begin{abstract}
Lambda$ renal myoepithelial hamartoma presented as a lucent filling defect with gross hematuria in an adult female. Preoperative studies caused conflicting impressions. The predominance of smooth muscle and incorporated tubuloepithelial elements characterize the tumor as a hamartoma of myoepithelial type. Pertinent review of the literature confirms the rarity of this lesion in adults.
\end{abstract}

Myoepithelial hamartoma is best described as part of a spectrum of benign renal lesions including hamartoma, leiomyoma, fibroma, lipoma, angioma, and adenoma. All occur rarely, but are particularly unusual when presenting as isolated, symptomatic lesions antemortem. Benign renal tumors when clinically significant can occur at any age. The youngest, a newborn, reported by Zuckerman et al.; ${ }^{1}$ the oldest, age eighty-one, reported by Bailey and Harrison. ${ }^{2}$ Foster, ${ }^{3}$ in a review of 135 cases, found an average age at presentation of thirtynine years, a 2 to 1 female predominance, and rarity in the black race with only 2 reported cases.

\section{Case Report}

A forty-four-year-old white woman was admitted to this Center for an evaluation of gross hematuria. Two weeks prior to admission the patient experienced two episodes of total, gross, painless hematuria. Evaluation by her private physician included normal findings on physical examination and persistent microscopic hematuria without bacteriuria. An excretory urogram showed deformity and smooth stretching of the left lower pole collecting system, suggestive of an intrarenal mass (Fig. IA). Tomography showed the mass was radiolucent and did not project beyond the renal margin (Fig. 1B). Outpatient ultrasonography was performed and showed a solid mass in the left lower pole (Fig. $1 \mathrm{C})$.

The patient was admitted for renal arteriography. Past medical history was unremarkable. Blood pressure was $126 / 76 \mathrm{~mm}$. Hg. Abdominal examination demonstrated no mass or tenderness. Urinalysis showed 5 to 7 red blood cells per high-power field and no other abnormalities. Serum creatinine was $0.7 \mathrm{mg} . / 100 \mathrm{ml}$., hemoglobin $13 \mathrm{Gm} . / 100 \mathrm{ml}$, and the white blood cell count 6,000 cells $/ \mathrm{mm}^{3}$.

Bilateral selective renal arteriography and venography were performed. Aortography showed displacement of the segmental arteries (Fig. 1D) and a $4-\mathrm{cm}$. radiolucent mass (Fig. 1E) in the lower part of the left kidney. The mass was avascular, and all arterial branches constricted with epinephrine infusion. Angiographic impression was that of a radiolucent avascular parapelvic cyst. Percutaneous "cyst" puncture and aspiration under local anesthesia were attempted but no fluid could be aspirated. Injected contrast media pooled around the needle tip suggestive of a solid lesion (Fig. 1F).

Because of these conflicting impressions a diagnosis of atypical hypernephroma or solid tumor of the kidney was considered. The patient underwent exploration via an anterior transperitoneal approach, and a firm area in the left lower pole was exposed via a nephrotomy. This revealed a pearly white, solid tumor, 

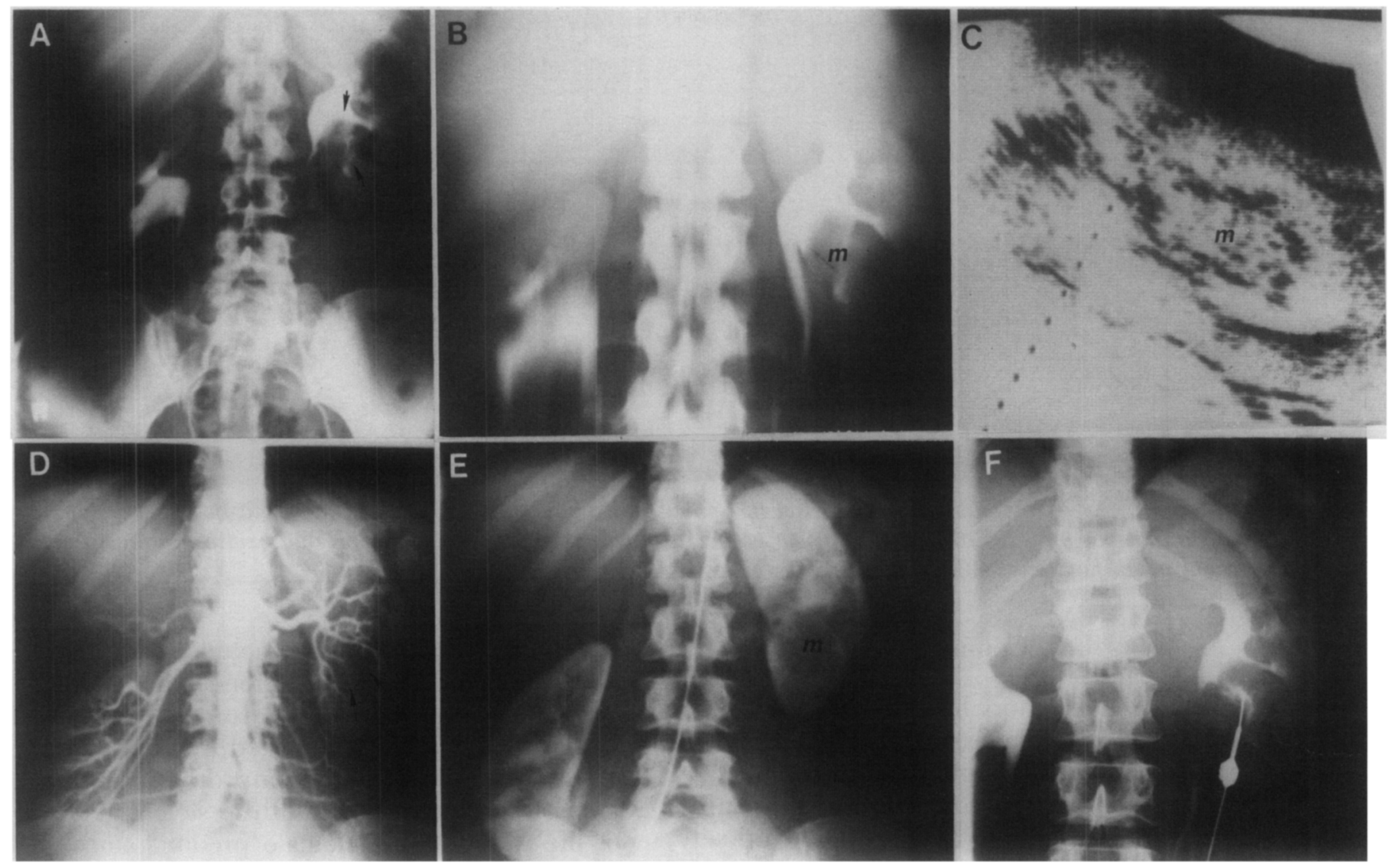

FIGURE 1. Excretory urogram, fifteen-minute radiograph; left lower pole lucent mass is evident with distortion of loteer renal peltis and calyces (arrotss). (B) Tamogram, $8 \mathrm{~cm}$. cut. Mass (m) more clearly defined with left renal pelvis and lower pole calyceal distortion. (C) Prone, longitudinal, left renal sonogram shous solid mass (m) in region of lower pole. (D) Aortogram, arterial phase. There is splaying of segmental arteries around left louer pole mass (arrouss), but no neovascularity. (E) Nephrographic phase of aortogram demonstrates left lower pole mass $(m)$ to be avascular. $(F)$ Left renal "cyst" puncture during excretory urography. Solid nature of le'sion is de'monstruled by pooling of injected contrast medium around needle tip.

seemingly fixed to a lower pole calyceal infundibulum (Fig. 2). Frozen section biopsy was interpreted as benign supporting tissue tumor. probable leiomyoma. The exact nature of the

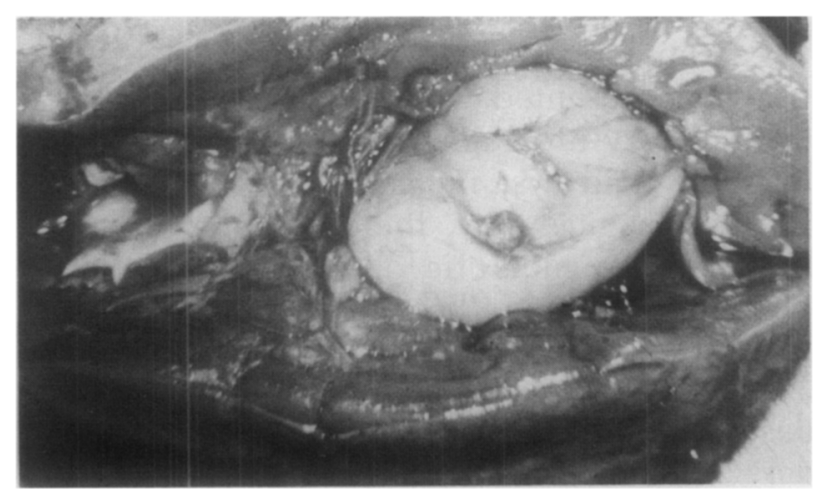

Figure 2. Lesion in situ. Left lower pold has been biralierl. entire tumor was not clear, and a simple nephrectomy was performed. Postoperative recovery was unremarkable, and the patient was discharged on the sixth postoperative day.

The gross specimen consisted of a $198-\mathrm{Gm}$. kidney with a smooth cortical surface. A 3.5 by 2.7 by $2.4-\mathrm{cm}$. firm, white mass with a whorled pattern and several small cysts was noted in the medulla. The mass distorted but did not involve the calyces. Microscopically, a circumscribed but nonencapsulated nodule was present in the renal medulla. It consisted of interlacing bundles of smooth muscle, tubular structures, and cysts of variable size. A trichrome stain confirmed the presence of smooth muscle. The various components had a benign histologic appearance, and were interpreted as a myoepithelial hamartoma. The adjacent renal parenchyma exhibited no significant abnormality (Fig. 3). 

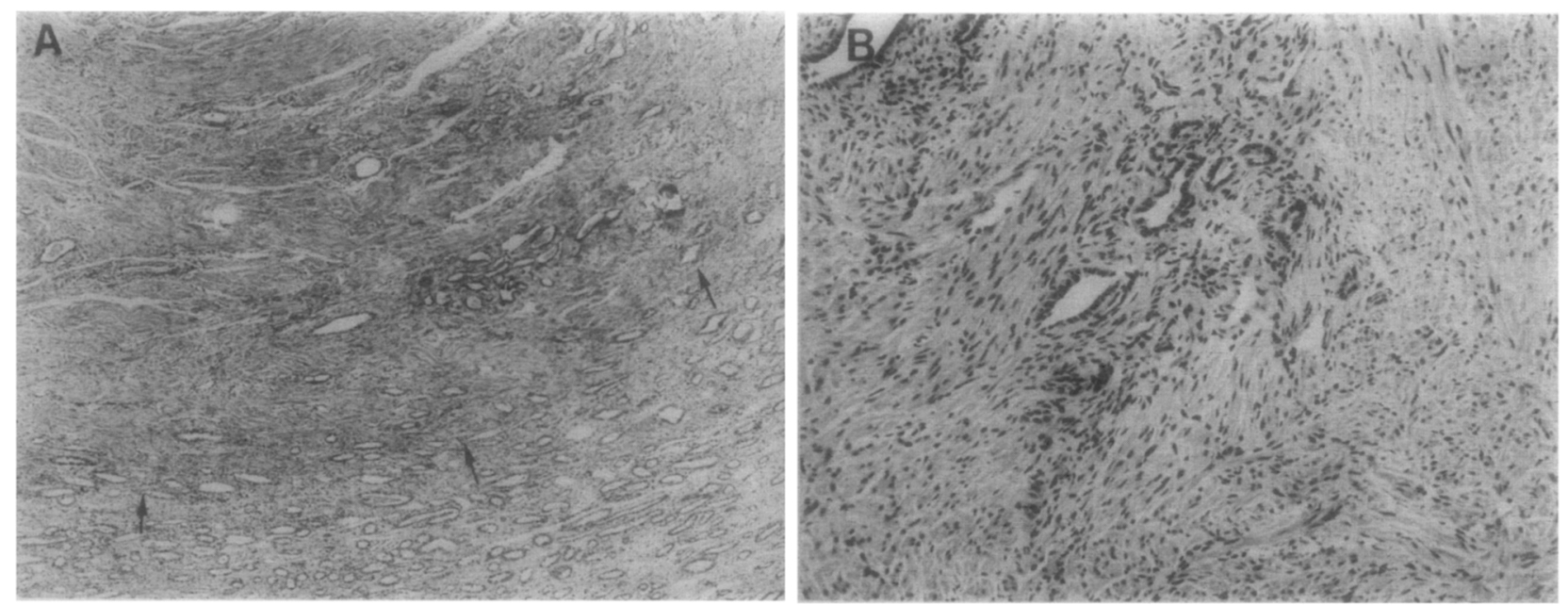

Figure 3. (A) Arrows at interface between hamartoma above and kidney parenchyma below. (B) Hamartoma consists of bundles of smooth muscle associated with tubular structures. (Hematoxylin and eosin stain, original magnifications $\times 30$ and $\times 162.5$, respectively.)

\section{Comment}

Benign renal tumors have been classified and characterized by Fuchsman and Angrist ${ }^{4}$ who separated them into epithelial and connective tissue types. A third group described as mixed with combinations of smooth muscle, tubuloepithelial elements, fibrous stroma, and adipose tissue, include the hamartoma. Hamartomas were described by Albrecht ${ }^{5}$ and Robbins $^{6}$ as tumor due to overdevelopment of some tissue elements which normally belong at the site where found, or to an abnormal relationship of a normally situated tissue element. Angiomyolipona, coined by Morgan, Straumfjord, and $\mathrm{Hall},{ }^{7}$ represents a specific type of hamartoma with the histologic features of smooth muscle, vascular, and adipose tissue in varying proportions. It falls within the broad definition of hamartoma and the two are often used interchangeably in the literature. Recent reviews by Price and Mostof ${ }^{8}$ and Bissada et al. ${ }^{9}$ confirm the general acceptance of an embryonal origin of these tumors.

Reports of clinically significant renal hamartoma have been few. Initial reports of such a lesion were published in 1942 by Moolten ${ }^{10}$ in association with tuberous sclerosis - a complex characterized by epilepsy, mental retardation, adenoma sebaceum, and "tumor-like malformation in various organs," including the kidney.

Fikner, ${ }^{11}$ Mallory, ${ }^{12}$ Rusche, ${ }^{13}$ Fuller,${ }^{11}$ and Hulse and Patik, ${ }^{14}$ were the first to report isolated cases of symptomatic renal hamartoma without associated tuberous sclerosis. Over one hundred forty-five such cases have since been published. Presentations included flank pain, flank mass, acute retroperitoneal hemorrhage, hypertension, acute pyelonephritis, and hematuria in order of reported frequency. ${ }^{8}$

Clinically, cases of symptomatic isolated hamartoma occur in the fifth to seventh decade of life with a 4 to 1 female predominance and equal distribution with respect to right and left renal involvement. They are frequently large in size, unifocal, and unilateral. ${ }^{15}$ When associated with tuberous sclerosis, they have an equal sex distribution; if symptomatic, they tend to present at an earlier age, are frequently small, multifocal, and bilateral. Microscopically, both isolated cases and those associated with tuberous sclerosis have been typical angiomyolipomas. ${ }^{8}$ The presence of tubuloepithelial elements in our case is more consistent with a true hamartoma and has not previously been reported except in children, ${ }^{16}$ where a diagnosis of Wilms tumor was initially considered. Long-term follow-up, up to eleven years in the Price and Mostofi series, ${ }^{8}$ confirms the benign nature of these tumors.

When presented with a lucent filling defect on excretory urography that is solid by ultrasonography and cyst puncture, but avascular by selective angiography, the differential diagnosis must include necrotic or avascular hypernephroma, sarcoma, benign solid tumor, and polycystic kidney disease. ${ }^{9,15,17,18}$ Angiographic characteristics peculiar to hamartoma have been described. ${ }^{19}$ A recent review of 26 cases found only 32 per cent with one or more of the typical findings, and 68 per cent with neovascularity indistinguishable from hypernephroma. ${ }^{20}$ Fewer 
than 5 cases have been correctly diagnosed preoperatively. Management can thus be difficult and may require exploration to resolve the issue. Although approaches to diagnosis and management are well reviewed by $\mathrm{McCul}$ lough, ${ }^{17.21}$ the variable clinical and pathologic spectrum of isolated renal hamartoma make individualization necessary - particularly when, as in this case, sophisticated diagnostic techniques are inconclusive.

Ann Arbor, Michigan 48109 (DR. FISCHER)

\section{References}

1. Zuckemuan IC, Kershner D, Laytner B, and Hirschl D Le'iomyoma of the kidney. Ann. Surg. 126: 220 (1947)

2. Bailey OT, and Harrison JH: Large benign renal neoplasm, J. Urol. 38: 509 (1937)

3. Foster DG: Large benign renal tumors: a review of the literature and report of a case in childhood, ibid. 76: 231 (1956).

4. Fuchsman JJ, and Angrist A: Benign renal tumors, ibid. 59: 167 (1948).

5. Albrecht E: Ueber Hamartome, Verhandl. Dtsch. Ges Pathol. 7: 15.3 (1904)

6. Robbins SL: Pathology, 3rd cd., Philadelphia, W. B. Saunders. 1967, p. 492

7. Morgan CS, Straumfjord JV, and Hall EJ: Angiomyolipoma of the kidney, J. Urol. 65: 525 (195l)

8. Price EB. Jr, and Mostofi FK: Symptomatic angiomyolipoma of the kidney, Cancer 18: 761 (1965)

9. Bissada NK, et al: Tuberous sclerosis complex and renal angionyolipoma, Urology 6: 105 (1975).

10. Moolten SE: Hamartial nature of the tuberous sclerosis complex and its bearing on the tumor prohlem. Report of a case with tumor anomaly of the kidney and adenomasebaceum, Arch Intern. Med. 69: 589 (1942).

11. Eikner WC: Renal hamartona, N.Y. Stat: J Med. 57: 3675 (1957).

12. Mallory TB: Clinical pathologic exercises $\backslash$. Engl J. Med. 240: 891 (1949).

13. Rusche C: Renal hamartoma angiomyolipoma) report of three cases, J. Urol, 67: 823 (1952).

14. Hulse LA and Patik EE: Renal hamartoma ibid 66: 506 (1951)

15. Scott MB. Halpern M, and Cosgrove MD: Renal angiomyolipona: two varieties. Urology 6: 768 (1975).

16. Bogdan R, Taylor EEM, and Mostofi FK: Leiom vomatous hamartoma of the kidney, Cancer 31: 462 (1973).

17. McCullough DL: Renal hamartoma, current concepts of diagnosis and surgical management, Urology 6: 235 (1975)

18. Bredin HC, Lavengood RW, Jr, and Barondess JA: Renal hamartoma, arteringraphic findings suggesting hypernephroma. ibid. 2: 574 (1973).

19. Viamonte M, Jr, Ravel R, Politano V, and Bridges B: Angiographic findings in a patient with tuberous sclerosis, Am. J. Roentgenol. 98: 723 (1966)

20. Clark RE, and Palubinskas $\mathrm{AJ}$ : The angiographic spectrum of renal hamartoma, ibid. 114: 715 (1972)

21. McCullough DL, Scott R, Jr, and Seybold HM: Renal angiomyolipoma (hamartoma), J. U rol. 105: 32 (1971 